\title{
¿Hacia dónde mirar?
}

Ana Victoria Cantero Domínguez | Dirección General de Patrimonio Cultural, Consejería de Educación y Cultura, Gobierno de Extremadura

URL de la contribución <www.iaph.es/revistaph/index.php/revistaph/article/view/3412>

Quizás los problemas más graves de la situación del patrimonio cultural en nuestro país, que por otra parte han existido siempre, agudizados en este momento por la crisis económica, radiquen en la inexistencia de un planteamiento global de futuro por parte de los poderes públicos, en el escaso o nulo protagonismo de la población en los procesos patrimoniales y en la inexistente participación de especialistas, distintos a los que hasta ahora tutelaban y gestionaban el patrimonio; agentes que podrían provenir del sector privado y con los que habría que determinar nuevos lazos de relación, en los que conciliar la conservación del patrimonio y la sostenibilidad medioambiental con las nuevas perspectivas económicas y sociales que conlleva la explotación turística, caballo de batalla, que en ocasiones se ha convertido en un factor de destrucción de patrimonio.

Es evidente, baste remitirse a los datos anualmente publicados por los organismos competentes, que el patrimonio cultural en sus diferentes dimensiones es una fuente de recursos que, vinculado al turismo, es uno de los sectores que mejor resiste la crisis, posibilita un desarrollo integral y sirve como motor de generación de riqueza, en un país como el nuestro en el que cada día es más complicado el mantenimiento de un tejido industrial competitivo.

Los poderes públicos en muchos casos resumen la inversión en patrimonio en la elaboración de actuaciones/soluciones para resolver lo inmediato, la urgencia, sin una visión más amplía, en la que definir una fase preventiva y una planificación que se adelanten a los problemas que pudieran surgir en cualquier estadio del proceso.

Un factor imprescindible sería el definir y acotar los límites o la implicación del intervencionismo de esos otros actores. Proceso en el que deberían estar presentes todos los especialistas implicados, de manera armónica, llegando a soluciones consensuadas, en las que convivan la conservación y protección del patrimonio histórico con el desarrollo turístico.

Es ahora un buen momento para actuar, planteando la crisis como un contexto de oportunidades, diseñando políticas turísticas que engloben varias líneas de actuación; una vez superada la dificultad de definición del ámbito de actuación, plantando las bases de futuras acciones con una serie de medidas a corto, medio y largo plazo, encaminadas a desarrollar estrategias de actuación y gestión que permitan planificar todos los procesos.

Previamente a la elaboración del plan de actuación, sería importante la revisión y reordenación cuantitativa y territorial de los recursos patrimoniales, para su mejor eficacia y optimización. Deberían plantearse las líneas de desarrollo o transformación necesarias que sirvan para una gestión sostenible del patrimonio cultural, conciliando la conservación con las nuevas perspectivas tanto económicas como sociales que abren las actividades relacionadas con el turismo, que entendemos podrían estar esencialmente enfocadas hacia:

- El desarrollo de proyectos conjuntos entre distintas entidades locales, constituyendo redes turísticas culturales en el ámbito rural.

- Diseñando nuevas formas de turismo tomando como base los recursos endógenos de los territorios.

- Diversificar la oferta turística, incluyendo nuevos territorios turísticos e implicando a nuevos sectores. 